Institute of $\mathbf{F}_{\text {ood and }} \mathbf{A}_{\text {gricultural }} \mathbf{S}_{\text {ciences }}$

\title{
Control and Automation in Citrus Microirrigation Systems ${ }^{1}$ \\ Brian Boman, Steve Smith, and Bill Tullos ${ }^{2}$
}

\section{Introduction}

Microirrigation (drip and microsprinklers) is the predominant method of irrigation for citrus in Florida. With chemigation, microirrigation systems can also provide an economical method of applying fertilizer and other agricultural chemicals on a timely basis. However, microirrigation systems require a higher level of management expertise than other irrigation methods. Microirrigation systems are more complex, require greater filtration and water treatment, and typically have high maintenance costs compared to other types of irrigation.

Irrigations generally must be scheduled more frequently with microirrigation systems, since they reach only a fraction of the root zone as compared to other types of systems. One way of managing the higher demands of microirrigation is the use of automation and central control systems. These technologies allow efficient control of water flows to various zones; injection of water conditioners, fertilizers, and agricultural chemicals; allow remote checks of system performance; control filter backflushing; and provide extensive records of water use. More sophisticated systems allow irrigations to be scheduled based on evapotranspiration (ET) calculations from nearby weather stations.

In many citrus microirrigation systems, a controller is an important and integral part of the irrigation system. Controllers can help to achieve labor savings in addition to applying water in the necessary quantity and at the right time to achieve high efficiency in water, energy and chemical uses. Irrigation controllers have been available for many years in the form of mechanical and electromechanical irrigation timers. These devices have evolved into complex computer-based systems that allow accurate control of water, energy and chemicals while responding to environmental changes and crop demands.

\section{Control Strategies}

Two general types of controllers are used to control irrigation systems: open control loop systems and closed control loop systems. Open control loop systems apply a preset action, such as is done with simple irrigation timers. Closed control loops receive feedback from sensors, make decisions and apply the results of these decisions to the irrigation system.

1. This is document No. CH194 and Circular 1413, one of a series of the Agricultural and Biological Engineering Department, Florida Cooperative Extension Service, Institute of Food and Agricultural Sciences, University of Florida. Publication date: July 2002. Please visit the EDIS Web site at http://edis.ifas.ufl.edu for additional publications related to citrus water management. This document can be accessed as http://edis.ifas.ufl.edu/CH194.

2. B. J. Boman, Associate Professor, Department of Agricultural and Biological Engineering, Indian River Research and Education Center, Ft. Pierce; Steve Smith, Aqua Engineering, Inc.; and Bill Tullos, Rain Bird Sales, Inc. Cooperative Extension Service, Institute of Food and Agricultural Sciences, Gainesville, FL 32611.

The Institute of Food and Agricultural Sciences is an equal opportunity/affirmative action employer authorized to provide research, educational information and other services only to individuals and institutions that function without regard to race, color, sex, age, handicap, or national origin. For information on obtaining other extension publications, contact your county Cooperative Extension Service office. Florida Cooperative Extension Service/Institute of Food and Agricultural Sciences/University of Florida/Christine Taylor Waddill, Dean. 


\section{$\underline{\text { Open Loop Systems }}$}

In an open loop system, the operator makes the decision on the amount of water that will be applied and when the irrigation event will occur. This information is programmed into the controller and the water is applied according to the desired schedule. Open loop control systems use either the irrigation duration or a specified applied volume for control purposes. Open loop controllers normally have a clock that is used to start irrigations. Termination of the irrigation can be based on a pre-set time or may be based on a specified volume of water passing through a flow meter.

Open loop control systems are typically low in cost and readily available from a variety of vendors. They vary in design and complexity and often offer flexibility as to the number of zones and how irrigations are schedules. The drawback of open loop systems is their inability to respond automatically to changing conditions in the environment. In addition, they may require frequent resetting to achieve high levels of irrigation efficiency.

\section{Closed Loop Systems}

In closed loop systems, the operator develops a general control strategy. Once the general strategy is defined, the control system takes over and makes detailed decisions of when to apply water and how much water to apply. This type of system requires feedback from one or more sensors. Irrigation decisions are made and actions are carried out based on data from sensors. In this type of system, the feedback and control of the system are done continuously.

Closed loop controllers require data acquisition of environmental parameters (such as soil moisture, temperature, radiation, wind-speed, etc) as well as system parameters (pressure, flow, etc.). The state of the system is compared against a specified desired state, and a decision whether or not to initiate an action based on this comparison. Closed loop controllers typically base their irrigation decisions on sensors that measure soil moisture status using sensors or use climatic data to estimate water use by plants. In some systems, both soil moisture sensors and climatic measurements are used.
The simplest form of a closed loop control system is that of an irrigation controller that is interrupted by a moisture sensor (Fig. 1). The sensor is wired into the line that supplies power from the controller to the electric solenoid valve and operates as a switch that responds to soil moisture. When sufficient soil-moisture is available in the soil, the sensor maintains the circuit open. When soil-moisture drops below a certain threshold, the sensing device closes the circuit, allowing the controller to power the electrical valve. When the controller attempts to irrigate, irrigation will occur only if the soil-moisture sensor allows it, which in turn occurs only when soil-moisture has dropped below acceptable levels.

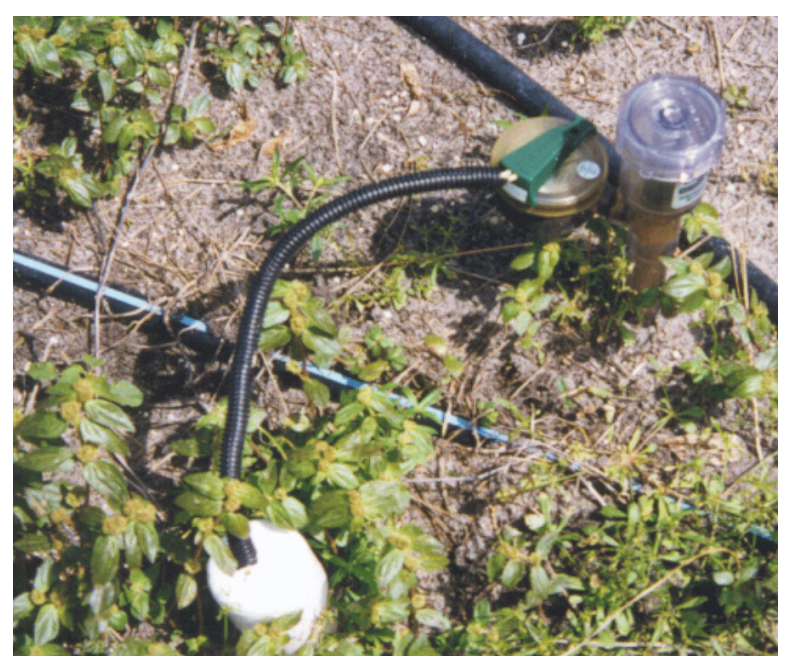

Figure 1. Switching tensiometer used to control irrigation system in microirrigated citrus grove.

\section{Controllers}

\section{$\underline{\text { Controllers }}$}

In the simplest form, irrigation controllers are devices which combine an electronic calendar and clock and are housed in suitable enclosure for protection from the elements. The controller provides a low-voltage output (typically 12 or 24 volts DC or 24 volts AC ) to the valves and control devices for specific zones. As long as the voltage is applied, valves stay open and irrigation water is applied.

Most remote control valves are "normally closed" meaning that the valve is closed until the solenoid is actuated by the controller. A "normally open" control valve remains open until such time as the solenoid is actuated. Normally open valves are 
sometimes used as master valves in systems when it is desirable to have a continuously pressurized mainline but still have a primary valve that can be closed in the event of excessive flow or other alarm conditions.

\section{$\underline{\text { Electromechanical Controllers }}$}

Electromechanical controllers (Fig. 2) use an electrically driven clock and mechanical switching (gear arrays) to activate the irrigation stations. These types of controllers are generally very reliable and not very sensitive to the quality of the power available. They generally are not affected by spikes in the power, and unless surges and brownouts are of such magnitude that they will damage the motor, they will continue to operate. Even if there is a power outage, the programmed schedule will not be lost and is generally delayed only for the duration of the power outage. However, because of the mechanically-based components, they are limited in the features they provide.

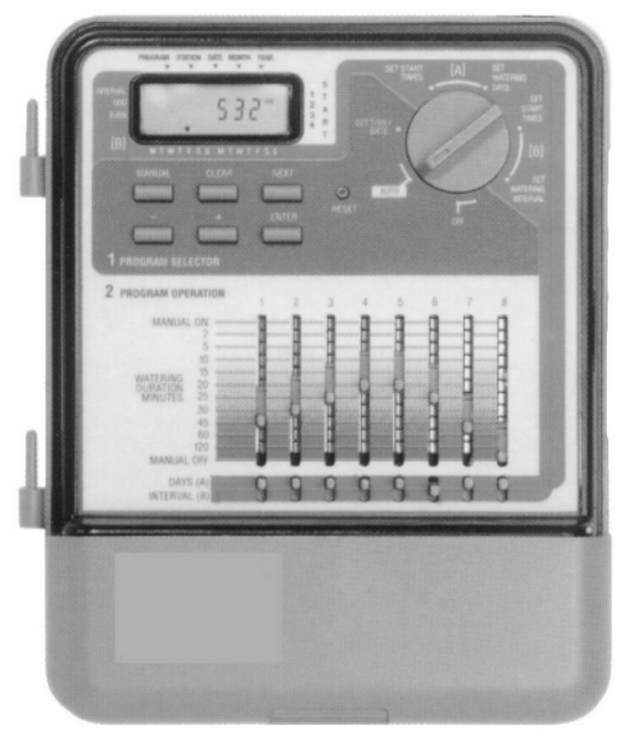

Figure 2. Electromechanical controller.

\section{Electronic Controllers}

Electronic controllers (Fig. 3) rely on solid state and integrated circuits to provide the clock/timer, memory and control functions. These type of systems are more sensitive to powerline quality than electromechanical controllers, and may be affected by spikes, surges and brownouts. Spikes and surges are common in many areas of Florida where lightning tends to be frequent and intense. These type of systems may require electrical suppression devices in order to operate reliably. Because of the inherent flexibility of electronic devices, these controllers tend to be very flexible and provide a large number of features at a relatively low cost.

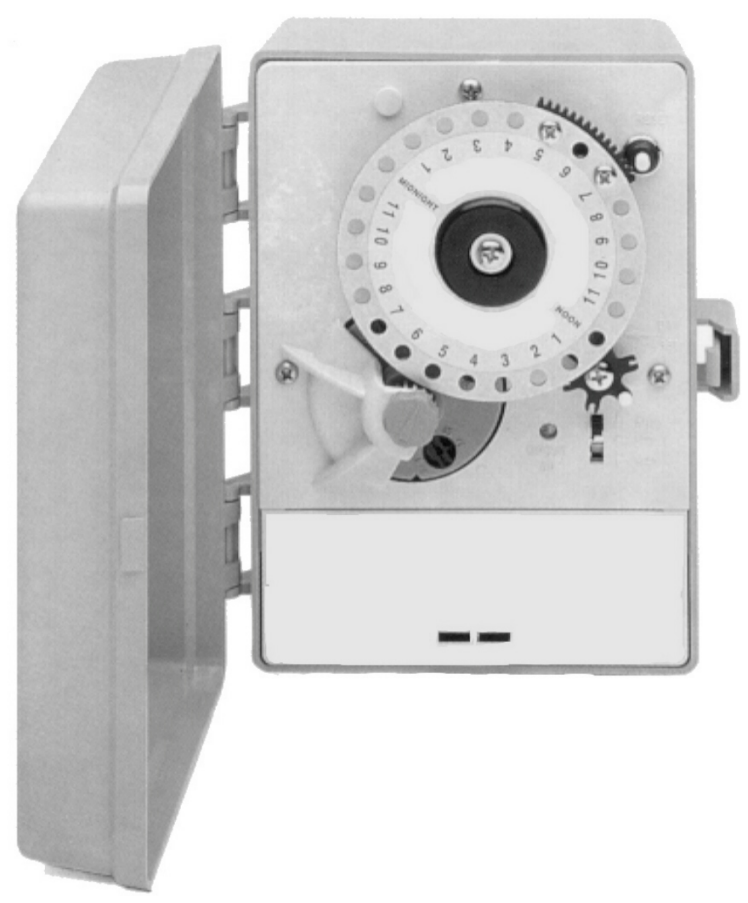

Figure 3. Electronic controller.

\section{$\underline{\text { Features }}$}

The basic minimum features of any independent irrigation controller is to provide the time of day, a day-of-the-week calendar, the ability to change the time setting on each station, and a means of physically connecting stations to valve wiring. Some models offer features that make changes in programming relatively simple. For example, a desirable feature is percent scaling. This feature allows a multiplier to be applied to the time setting on every station. Older model controllers without such a feature require that every station's time be set individually, which is time consuming and frustrating to the user. Some controllers allow for different percent scaling on each program, or valve group, within the controller.

With percent scaling, the system operator can go to the controller, key in a new percent scaling factor, and know that the time settings on all zones have been automatically reset for the time setting on that station multiplied by the percentage. For example, 
assume a certain zone has a time setting of 4 hours. If the percent scaling factor is programmed to be $75 \%$, then the valve will open for $4 \mathrm{hr} \times 75 \%=3.0$ hours. It is possible to easily make frequent program changes in response to tree, soil, cultural, and climatic factors when the percent scaling feature is available on the controller. For this reason, this simple feature can be very important in maintaining efficient irrigations.

Several designs of controllers are commercially available with many different features and over a wide range of costs. Most irrigation timers provide several of the following functions:

- A clock/timer that provides the basic time measurements by which schedules are executed.

- A calendar selector that allows definition of which days the system is to operate.

- A station time setting that defines the start time and duration for each station.

- Manual start functions that allow the operator to start the automatic cycle without disturbing the preset starting time.

- Manual operation of each station so the operator can manually start the irrigation cycle without making changes to the preset starting time.

- A master switch that prevents activation of any station connected to the timer.

- Station omission features that allow the operator to omit any specified number of stations from the next irrigation cycle.

- A master valve control feature that provides control to a master system valve. This function is used with certain types of backflow prevention equipment and also prevents flow to the system in case of failure in the system.

- Pump start features to allow a pump start solenoid to be activated whenever a station is activated, thus tying pump control with irrigation control.
Some controllers allow every station to be programmed independent of other stations, and some irrigation managers consider this feature to be quite important. Programming such a controller can be more complex and time consuming, but the flexibility may be worth it. Another feature provides for a single irrigation event to be broken up for brief periods of operation followed by brief periods of rest. In heavy soils, irrigating in this manner allows the irrigation application rate to more closely match the soil's intake characteristics. This type of control can also be important for drip systems in flatwoods areas where root zones are limited. For example, if a system needs to operate for 10 hours per day, the 10-hour duration might be broken into five 2-hour irrigation cycles separated by 2-hour non-irrigated periods. The water applied with this scenario will typically have more lateral movement and less vertical movement than if the water was applied in one setting. As a result, water will be used more efficiently, with less opportunity for leaching below the root zone of the trees. Other desirable features that are available on many of the more advanced controllers include provisions for:

- Multiple zones so that zones with young trees can be on completely separate operating schedules.

- Extended and flexible calendars that adapt to imposed restrictions that are mandated by water management districts such as every-third-day schedules or night-time only watering.

- Non-volatile memory that holds the time settings and program in the event of power loss.

- Easy setup and programming to allow input from rain and soil moisture sensors.

\section{$\underline{\text { Selection Criteria }}$}

Some controllers allow the addition of a hand held remote to facilitate repairs. For example, if a maintenance person completes a repair and wants to check the valve or the system performance, a hand held remote device can be used to start the valve without going back to the controller. The time saving aspects of such a device can often show a direct payback. 
When evaluating controllers to pick an appropriate system for a particular project, the following factors should be considered:

- Cost, quality, and warranty.

- Programming features.

- Total number of zones and the number of zones that can be operated simultaneously.

- Run time time increment.

- Enclosure (suitability to outdoor or indoor installation).

- Repair alternatives.

\section{Electrical Considerations}

Schedules must be programmed into the controller's memory where they are maintained as long as power is available. When a given zone or valve is to be opened, a voltage is applied between the controller's "common" position on the terminal strip and the selonoid for the valve. A volt-ohm meter can be used to verify that the voltage is available and that the controller is functioning as intended.

A terminal strip with a screw for each station provides the easiest approach to wire connections inside the controller (Fig. 4). Some controllers have a bundle of labeled wires that are attached to the appropriate solenoid using a wire nut. When voltage is applied to the station, the solenoid on the valve is actuated and allows the water passage in the pilot valve to open. The water pressure upstream of the valve is utilized to actually hydraulically open the valve. The voltage continues to be applied from the controller and the solenoid stays active or holds, for the full time increment set on the controller.

\section{$\underline{\text { Grounding and Surge Protection }}$}

In general, a controller should be grounded and should be protected from electrical surge (Fig. 5). The manufacturer should be consulted as to the specific recommendations for each piece of equipment. Solid-state electronics are more susceptible to lightning and power fluctuations than the older electro-mechanical designs. However, these

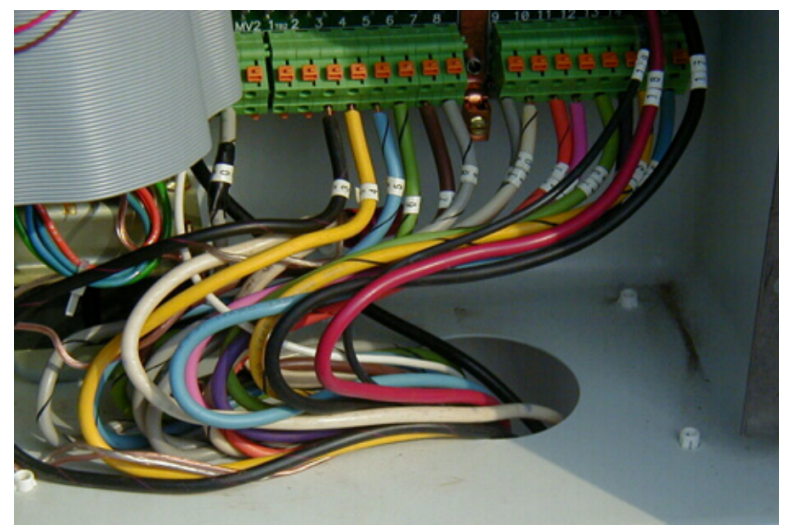

Figure 4. Multi-colored low-voltage wiring used to connect controller to valves and other control devices.

factors should not deter one from considering solid state controllers due to their flexibility. Controller manufacturers will generally recommend:

-8-foot copper clad ground rods installed next to the controller with the controller wired to ground using a heavy gauge wire and suitable connectors (three ground rods in a triangular grid can be used in order to acheive the recommended earth ground of $5 \mathrm{ohms}$ or less).

- A metal oxide varistor (MOV) installed on each valve wire to protect against electrical surge

- A MOV on the primary power input side to protect the controller's electronics

\section{Low Voltage Wire Characteristics}

Wiring used between the controller and the electric valve must be designated for direct burial (UF- underground feeder, describes wire that is suitable for direct burial by the National Electric Code).

To make maintenance easier, each controller in the system should use a consistent wire code scheme. Typically white is used for the common wire, while the control wire is some other unique color. A uniquely colored wire (as opposed to a whole bundle of wires having the same color) can be quickly located anywhere in the system. When there are many wires of the same color, wires must be checked one at a time to find the desired wire. A voltage (from a transformer or battery) can be applied and checked with a volt-ohm meter to identify specific wires. 


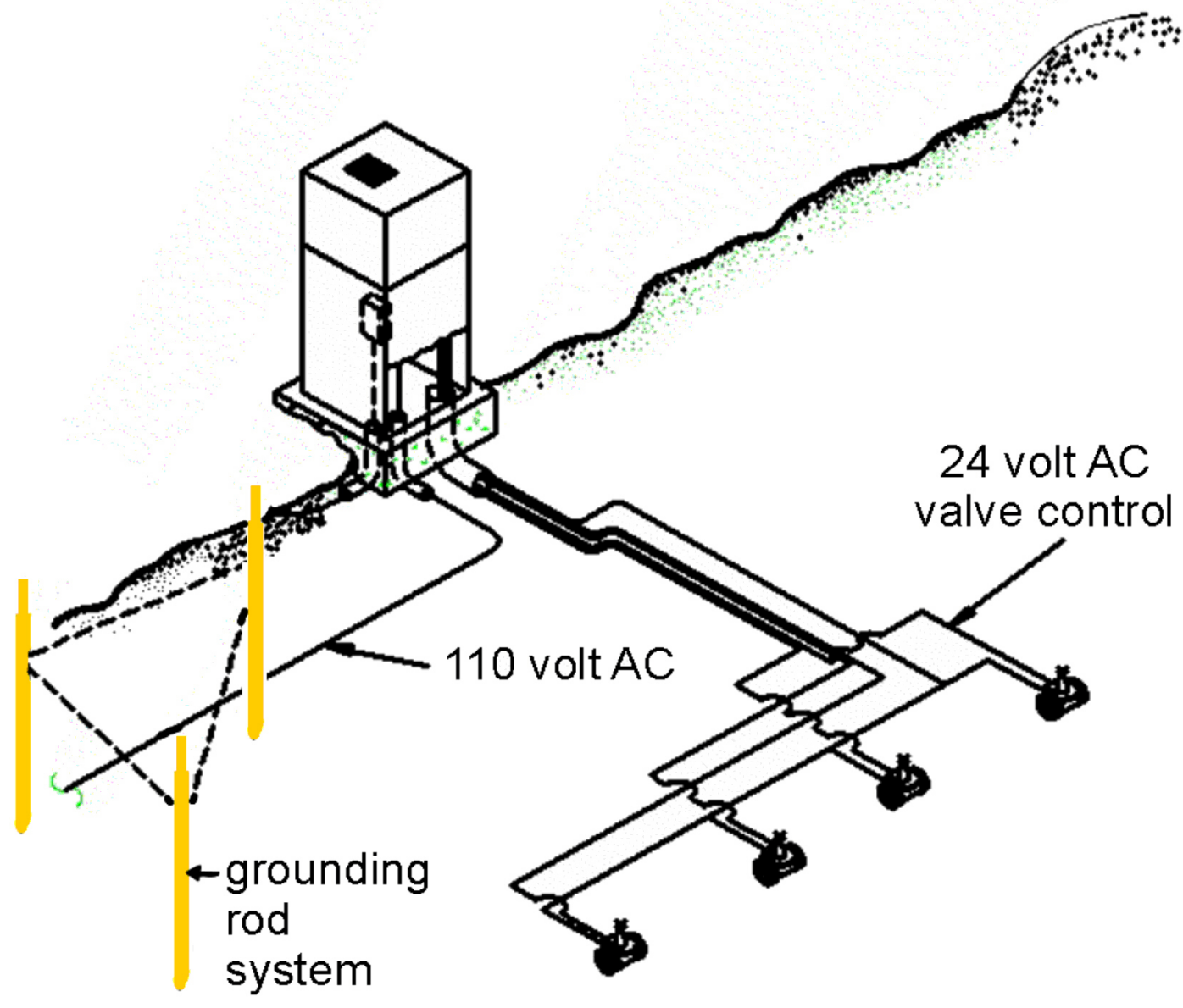

Figure 5. Typical grounding for 110 VAC controller.

For smaller projects having short wire runs, it is often practical to use multi-strand cable. Multi-strand cable is commonly available with 4-, 6-, 8-, 10-, and 12-wires. Wires should be labeled at the controller to indicate the valve to which they are attached.

\section{$\underline{\text { Wire Sizing }}$}

Typical wire sizes used in irrigation systems range from 8 to 18 American Wire Gauge (AWG) sizes. Normally, $18 \mathrm{AWG}$ is the smallest size used in irrigation systems (approximately 0.04 inch diameter) and $8 \mathrm{AWG}$ is the largest (approximately 0.13 inch diameter).

The major valve manufacturers have developed wire sizing procedures for their valves as an assist to irrigation system designers. It is best to utilize their resources when available because some of the procedure is based on testing of their valves and using their performance criteria. Sometimes valve wire is sized for reasons other than electrical properties.
Many maintenance personnel consider 14 AWG wire to be the minimum acceptable size for a purely subjective reason -- they believe a heavier (14 AWG or 0.06-inch diameter) wire is less likely to be damaged or cut when mainline or wire repairs are made.

The allowable voltage drop is the controller output voltage (typically 12 or $24 \mathrm{VDC}$ or $24 \mathrm{VAC}$ ) minus the minimum solenoid operating voltage (manufacturer specific). The inrush current is the current necessary to initially open the solenoid valve and this current increases as the water pressure increases because the solenoid works against the pressure. Wire resistance increases as the cross-sectional area of the wire decreases and the length of run increases. Wiring used in low voltage control circuits should be sized based on the following electrical properties: 
- Allowable voltage drop.

- Inrush current.

- Wire resistance.

\section{$\underline{\text { Wire Installation }}$}

Low voltage wiring should be installed below the mainline pipe in the irrigation system. The mainline pipe can protect the wiring from cutting or nicking. When wire is not protected by the mainline, it should be installed in conduit. A warning tape installed about 6 inches deep in the trench can provide further protection and an alert to excavators. Wire should also be installed in conduit when there is good chance of damage due to excavations or rodents. Wiring installed above grade should generally be in electrical conduit. High voltage and low voltage wire should always be installed in separate electrical conduits

Control and common wire should be looped at 45 and 90 degree turns in the trench to provide for expansion and contraction of the wire as the ground temperature changes. The wires should be taped at 6to 10-foot intervals to keep the wire together as a bundle. A nice installation technique at the valve is to produce an expansion coil by wrapping 2 to 4 feet of wire around a shovel handle or 1-inch pipe to produce a coil which has the appearance of a spring (Fig. 6). A further benefit of this technique is to allow the valve top to be removed without disconnecting the wires.

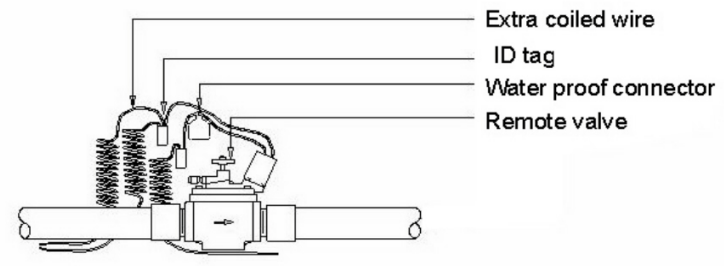

Figure 6. Coiled control wire and water proof connectors at remotely-activated electric valve.

All underground wire connections are made with waterproof connectors. There are many styles of water-proof connectors available. Select one that allows for a firm connection of the two (or three) wire ends and seals the connection in silicon rubber or a similar durable and water proof material. In larger systems with long wire runs, wire splices may be necessary at places along the mainline where there are no valves. In this case, wire splices should always be grouped together and installed in a valve box. The location of splices should be recorded on the as-built irrigation drawings at the completion of the installation.

\section{$\underline{\text { Trouble Shooting }}$}

Understanding the electrical characteristics of control systems facilitates trouble shooting of problems. Necessary tools and supplies include a volt-ohm meter, wire cutters and strippers, water proof wire connectors, and wire in various gauges and colors. Some irrigation controllers provide hints or even station lights that indicate shorts to ground in the control wire for a particular valve. Broken wires can often be tracked with equipment designed to find faults and shorts to ground. This equipment can also assist in finding valves or components that have been buried below ground.

\section{Sensors}

A sensor is a device placed in the system that produces an electrical signal directly related to the parameter that is to be measured. In general, there are two types of sensors: continuous and discrete. Continuous sensors produce a continuous electrical signal, such as a voltage, current, conductivity, capacitance, or any other measurable electrical property. Continuous sensors are used when just knowing the on/off state of a sensor is not sufficient. For example, to measure pressure drop across a filter (Fig. 7) or determe tension in the soil with a tensiometer fitted with a pressure transducer (Fig. 8) requires continuous-type sensors.

Discrete sensors are basically switches (mechanical or electronic) that indicate whether an on or off condition exists. Discrete sensors are useful for indicating thresholds, such as the opening and closure of devices such as valves, alarms, etc.. They can also be used to determine if a threshold of an important state variable has been reached. Some examples of discrete sensors are a float switch to detect if the level in a canal is below a minimum desirable level (Fig. 9), or a switching tensiometer (Fig. 10) to detect if soil moisture is above a desired threshold. When combined with time, pulses from switches can be used to measure rates such as the 


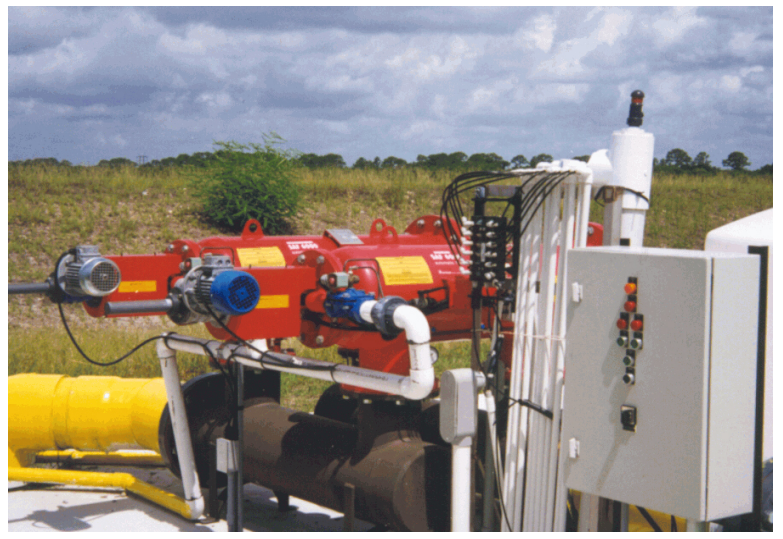

Figure 7. Control panel for automatically backflushing filters based on pressure differential between inlet and outlet of filter.

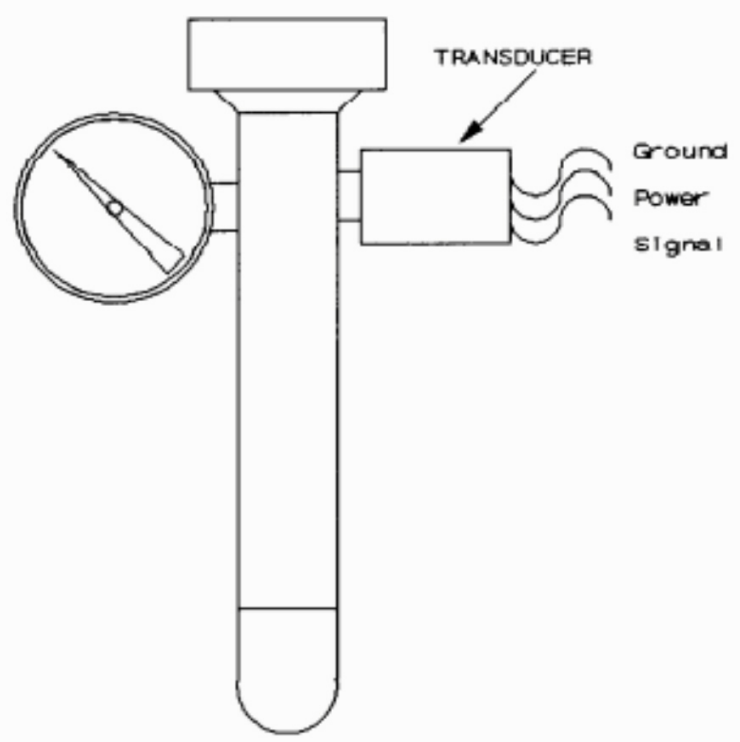

Figure 8. Tensiometer fitted with pressure transducer to provide continuous feedback of soil tension status.

volume of fuel, water or chemical solution passing through a totalizing flow meter with a magnetically activated switch.

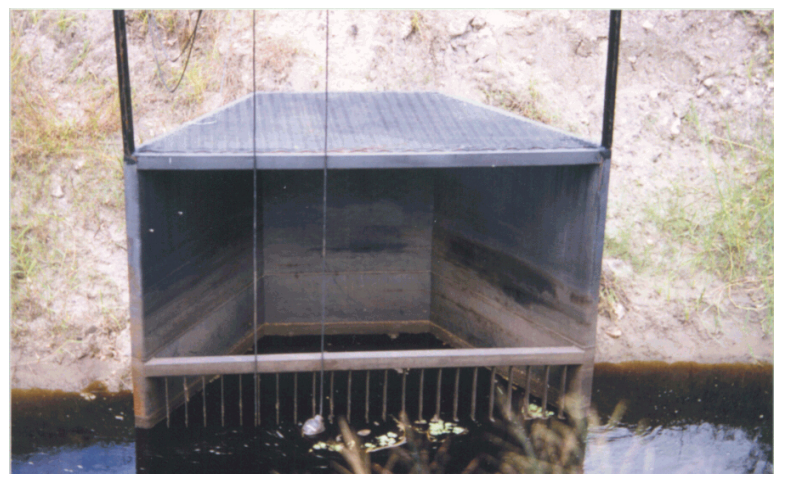

Figure 9. Float controls for drainage pump.

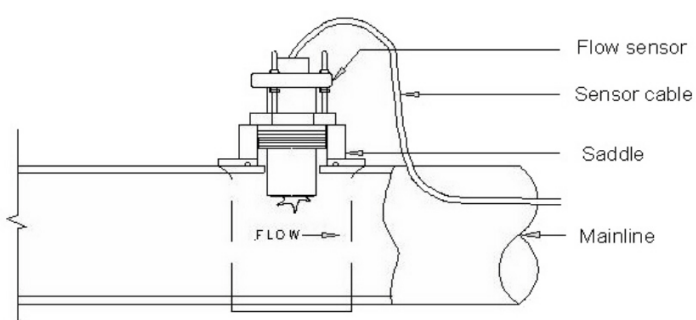

Figure 10. Paddle wheel flow sensor installed in mainline allowing remote monitoring of flow rate in system.

Sensors are an extremely important component of the control loop because they provide the basic data that drive an automatic control system. Understanding the operating principle of a sensor is very important. Often, sensors do not react directly to the variable being measured. The ideal sensor responds only to the sensed variable, without responding to any other change in the environment. It is also important to understand that sensors always have a degree of inaccuracy associated with them and they may be affected by other parameters besides the "sensed" variable.

Some of the variables that are often measured in computer-based control systems are: flow rate, pressure, soil-moisture, air temperature, wind speed, solar radiation, relative humidity, conductivity (total salts) in irrigation water, and $\mathrm{pH}$ of irrigation water.

The measurement of flow rate in the mainline (Fig 11) is one of the most important measurements in an irrigation system. Flows that are out of range, either high or low, can be reported and acted upon. Flow sensors can be read remotely by control system hardware designed with this feature or by adding interface hardware. Typically, flow sensors utilize a paddle or propeller inserted into the water stream that turns with the RPM (revolutions per minute) directly related to the flow velocity. Electrical pulses are generated by the sensor relative to the RPM. Remotely read flow meters of this type are often added even if existing manually-read flow meters are already included in the system (sometimes required by the water management districts). High flow or low flow alarms are possible when the flow meter is integrated with the control system.

Software used with the control system can continually check on the flow rate in the system and 


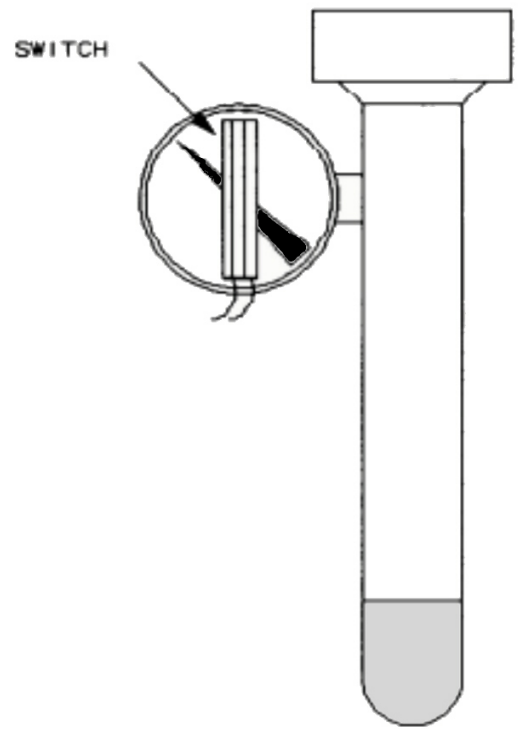

Figure 11. Tensiometer fitted with a switch to provide a discrete on/off status of the soil moisture.

compare it to pre-defined acceptable levels. High flow conditions indicate pipe failures or stuck valves. Since the results of broken mainlines can be disasterous (erosion, washouts, etc.), systems are often programmed to shut down when high flows(25-30\% above normal) are detected. A high flow condition, recognized by the central controller, can close a master valve or shut the pump down to prevent further flow. Such action, when coupled with an alarm report issued to the central computer operator, can be quite effective in responding to a high flow and subsequently effecting a timely repair.

Wind sensors can prevent or terminate irrigation if a specified wind develops and is sustained. Rain sensors can prevent irrigation during or after significant rain. Soil moisture sensors can prevent irrigation when adequate soil moisture is already present. Sensors can be used to detect pressure and shut the system down if the pump is not primed or initiate flush cycles in filters.

Figure 12 shows a simple and low cost rain sensor. Rain causes the porous disks in the device to swell and open a micro-switch. The switch remains open as long as the disks are swollen. When the rain has passed and the ET rate is back up, the disks dry out and the switch again closes. This device can be implemented in two ways. With central control the switch closure can be read by the central system which in turn can be programmed to effect a rain shutdown at one or more sites. With an independent controller, the device can be installed at or near the controller and as a switch on the common wire. In this way, irrigation is prevented because the circuit is not completed when the switch is open.

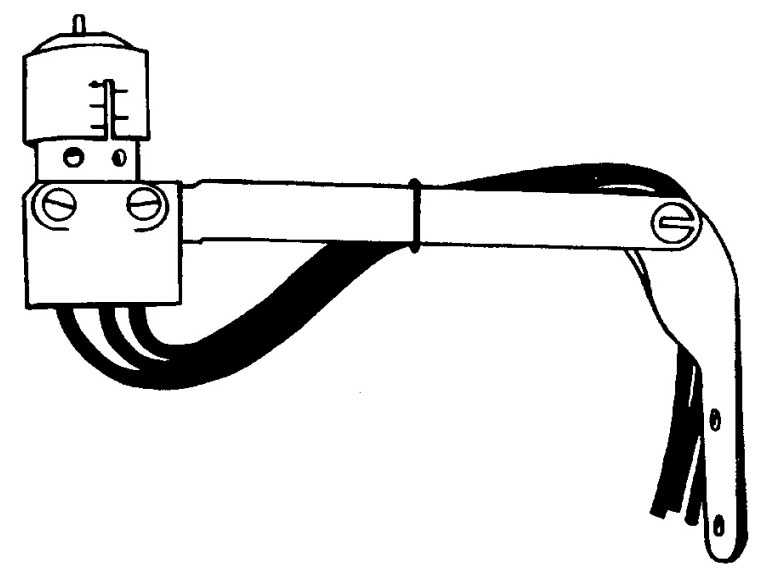

Figure 12. Rain shut-off switch.

\section{A/D Interface}

Since computer systems work internally with numbers (digits), the electrical signals resulting from the sensors must be converted to digital data. This is done through specialized hardware referred to as the Analog-to-Digital (A/D) interface.

The A/D interface converts discrete signals resulting from switch closures and threshold measurements into digital format, either 0 or 1 . Continuous electrical (analog) signals produced by the sensors signals are converted to a number related to the level of the sensed variable. The accuracy of the conversion is affected by the resolution of the conversion equipment. In general, the higher the resolution, the better the accuracy.

An 8-bit resolution A/D board is capable of dividing the maximum input voltage in $2^{8}$, or 256 increments. For, example if a pressure sensor produces a voltage signal ranging from 0 to 5 volts for a range of pressure of $50 \mathrm{psi}$, an 8-bit resolution $\mathrm{A} / \mathrm{D}$ board will be able to detect a change in voltage of about $5 / 256$ volts which will result in measurable increments of 50/256, or 0.2 psi. If the resolution of the A/D board was 12-bit, the board would be able to detect a change in voltage of about $5 / 2^{12}$ volts, or a measurable increment of 50/4096, or 0.01 psi. 


\section{Computer-based Irrigation Control Systems}

A computer-based control system consists of a combination of hardware and software that acts as a supervisor with the purpose of managing irrigation and other related practices such as fertigation and maintenance. Generally, the computer-based control systems used to manage microirrigation systems can be divided into two categories:

- Interactive systems that collect and process information from various points in the system, and allow manual control of the system from a central point by remote operation of valves or other control devices.

- Fully automatic systems that control the performance of the system by automatically actuating pumps, valves, etc. in response to feedback received from the monitoring system. These systems use closed control loops which include:

- Monitoring the state variables (pressure, flow, etc.) within the system.

- Comparing the state variables with their desired or target state.

- Deciding what actions are necessary to change the state of the system.

- Carrying out the necessary actions.

Performing these functions requires a combination of hardware and software that must be implemented for each specific application.

\section{$\underline{\text { Interactive Systems }}$}

Interactive systems are usually built around a microcomputer, either a standard personal computer (PC) or a specially designed unit. The information is transferred into a central unit either directly from sensors in the pipeline or from intermediate units which collect the data from a number of sensors and then process and store them temporarily for further transfer to the central computer. These systems have features that enable the operator to transmit commands back to the various control units of the irrigation system. The field devices such as valves (Fig. 13), regulators, pumps, etc. are fitted with electrically operated servo-devices which enable actuation of the pumps, closing and opening of valves, and adjusting pilot valves of flow regulators. This type of system permits the operator to govern the flow from the central computer by controlling flow parameters such as pressure and flow rate, according to specific needs at the given time, and to receive immediate feedback on the response of the system.

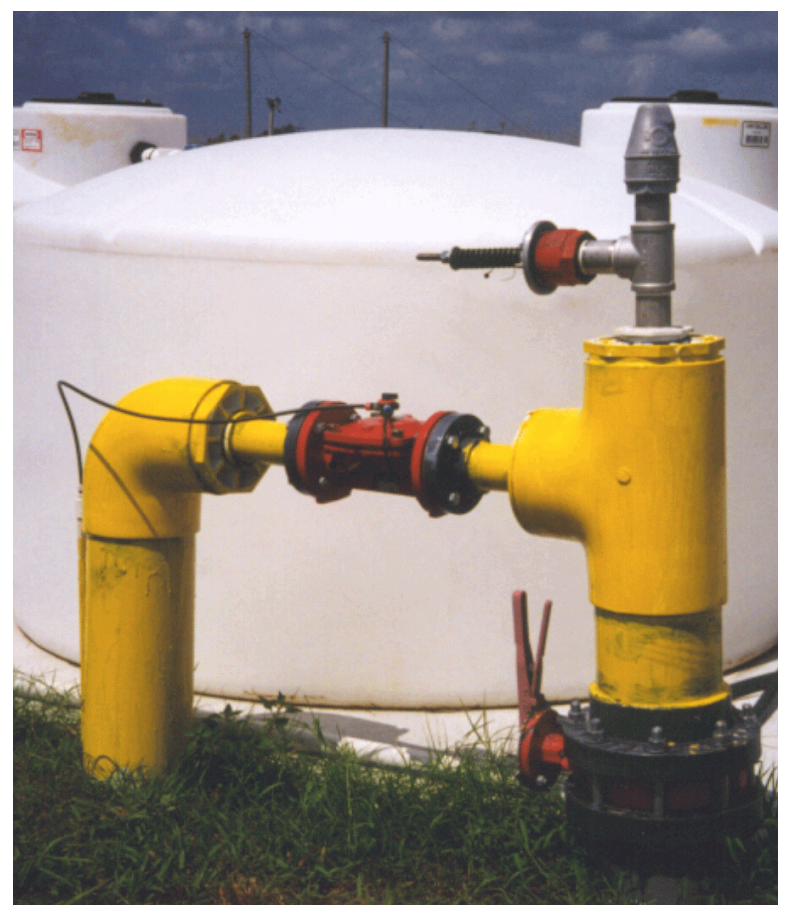

Figure 13. Hydraulically actuated control valve with vacuum and pressure relief valves downstream.

\section{$\underline{\text { Automatic Systems }}$}

In fully automated systems (Fig. 14), the human factor is eliminated and replaced by a computer specifically programmed to react appropriately to any changes in the parameters monitored by sensors. The automatic functions are activated by feedback from field units and corrections in the flow parameters by control of devices in the irrigation system until the desired performance level is attained. Automatic systems can also perform auxiliary functions such as stopping irrigation in case of rain, injecting acid to control $\mathrm{pH}$, sounding alarms, etc. Most control systems include protection in emergencies such as loss of the handled liquid due to pipe burst. They close the main valve of the whole system or of a 
branching, when an unusually high flow rate, or an unusual pressure drop is reported by the sensors.

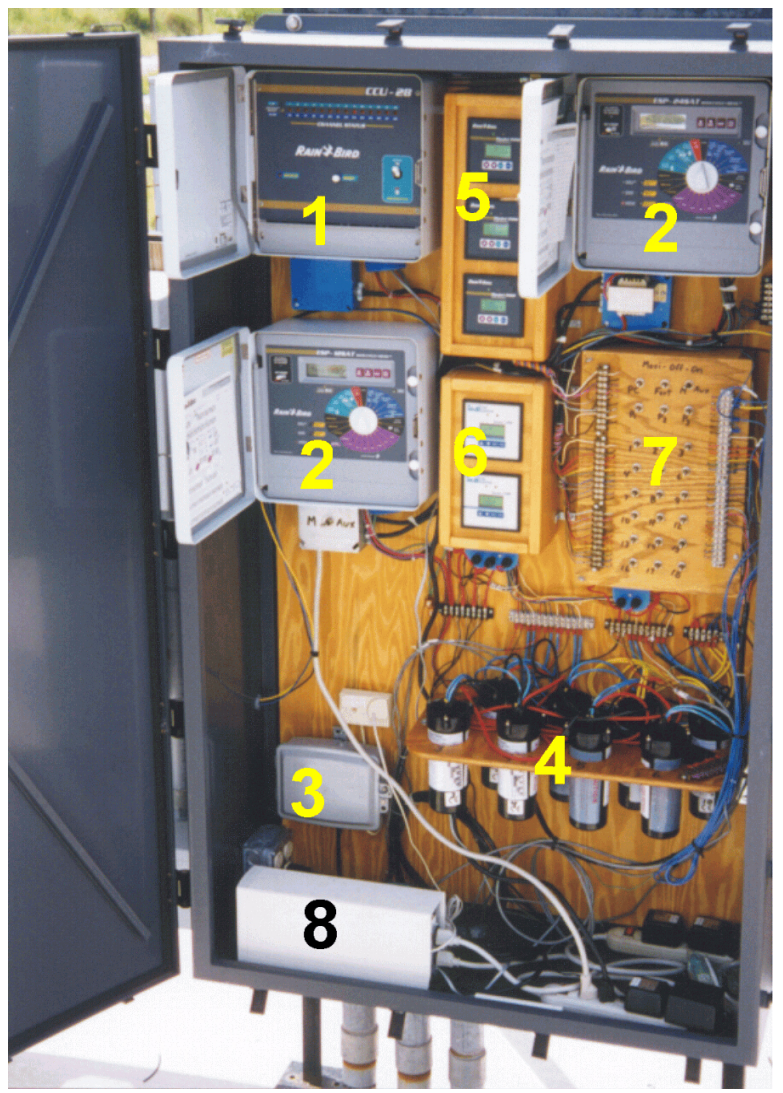

Figure 14. In-field controls for a centrally-controlled citrus irrigation system including: 1) on-site communication, data storage, and control device; 2) valve, pump, and accessory controllers; 3) phone connection; 4) sensor decoders; 5) flow monitors; 6) pressure and water level monitors; 7) manual over-rides; 8) power conditioning and surge protection.

\section{$\underline{\text { Selection of a Central Control System }}$}

In determining the best control system for a specific project and management group, the first thing to recognize is that an informed decision will be time consuming. If the end user already has favorable experience, training, or familiarity with a specific control system, manufacturer, or distributor, he/she should probably make decisions based on the experience. If the end user is open and unbiased and wishes to make a sound decision based on an objective evaluation of capabilities, costs, and overall effectiveness, then he/she should be prepared to put appropriate time into the effort to determine the most suitable system for his/her specific needs.

\section{Centralized Irrigation Control}

Water shortages and rising power costs demand increased attention to sound water management. Large groves functioning under one management group should be particularly alert to their water management strategy. Centralized irrigation control is not only an appropriate tool for improving water management but other objectives can be accomplished at the same time.

There are many central control systems to choose from and the user base is very large and geographically diverse with hundreds of systems throughout the country. Basic technical capabilities, reliability, and cost effectiveness have been demonstrated repeatedly to the satisfaction of even the most skeptical.

An irrigation central control system can be simply defined as a computer system which operates multiple controllers, sensors, and other irrigation devices from one central location. Today's central control system can monitor conditions in the system and surrounding areas, then control the equipment to properly respond to the conditions. This "monitor and control scenario" allows for complete system automation wherever parameters can be defined for system operation. The system can operate without personal intervention.

The monitor function of a central control system may consist of many different sensors: wind sensors, weather stations, and rain sensors are just a few of the options available. These sensors monitor their respective areas and report current conditions. The system can respond if any of the conditions are outside pre-defined limits. An example of sensor operations is the ability of the system to monitor rainfall. If rain occurs in a given area, the system can automatically turn off the irrigation in that area and report its actions to the central control system.

Controlling the system from the central location allows all system operations to be programmed and monitored easily and efficiently. Control actions such as adjusting watering times at all sites for seasonal fluctuations can be accomplished easily by one person from each location. 


\section{$\underline{\text { Central Control Components }}$}

Central control systems consist of a central computer, communications equipment, field controllers, and sensors. The central computer is usually located in the irrigation manager's office. The communications equipment is located both at the computer and at the field devices. Communications equipment can consist of telephone modems, radio modems, or fiber-optic modems. A middle manager device called the cluster control unit, which receives information from the central computer, is located on-site to monitor and control the system equipment. These field devices are connected to irrigation valves, sensors, and other field equipment.

Weather stations can be monitored by the central computer to gather weather information and automatically calculate irrigation watering times. By gathering weather data and automatically adjusting the system, large amounts of water and money can be saved.

Most central control systems run on PC-compatible computers. In general, a faster computer with more RAM is required than in the past. Most new users purchase a high speed computer that has plenty of hard disk capacity, additional RAM, CD drives, and a suitable backup system.

Certain minimum capabilities can be assumed from most of the central control systems available now. Most systems provide reliable radio and telephone communication with remote sites, percent scaling to quickly accomplish day-to-day and system-wide changes in scheduling, and greatly expanded instrumentation possibilities that are limited only by imagination and budget. Percent scaling is usually possible at multiple levels. For example, a percent scaling factor may be applied globally to the entire system and another percent scaling factor may be applied to individual sites.

Figure 15 represents a central control system coupled with an on-site weather station or an accessible local weather station network. Together, the control system and the management system offer the potential of scheduling irrigations more closely and reactively than with any other approach. In the representation, climatic data are gathered from a weather station, and the daily reference evapotranspiration rate $\left(\mathrm{ET}_{\mathrm{o}}\right)$ is calculated and utilized in making irrigation decisions. Irrigations can be rescheduled daily or even during the course of a single day to accommodate rainfall, changes in ET, or even subjective judgments on the part of the system operator or irrigation manager.

In fact, many central control systems can be configured to automatically use ET ${ }_{0}$ data to calculate crop water use and make adjustments to the run times of each zone. Whether or not a given project should be configured to perform in this way depends on people and management philosophies. While such a control system is capable of managing irrigation effectively without intervention by personnel, regular inspection (e.g. daily) by knowledgeable operators may prevent serious problems from developing.

\section{$\underline{\text { New Capabilities }}$}

Users do have numerous new capabilities to consider in central control. The look and feel of systems has been constantly improved--some dramatically improved. Pop down menus, point and click (mouse) applications, and icon-driven menus are now common. New capabilities come quickly in response to wish lists from current or potential users.

Specialized consultants are available to help with initial data input and long term modifications and advice. Their services include determination or measurement of: lateral precipitation rate, soil infiltration rates, lateral flow rates, and system hydraulic limitations. The initial control program can be developed and entered based on design drawings, field work, or a combination of both. Most consultants are available to provide follow-up support, training, and trouble shooting.

Some manufacturers provide an accreditation program to train and expand the knowledge base of consultants actively working with central control systems. Certification by the manufacturer is a means of promoting the service and an indication of the competence and proficiency of the consultant. Consideration should be given to the reputation of the consultants, manufacturer representatives, and dealers 


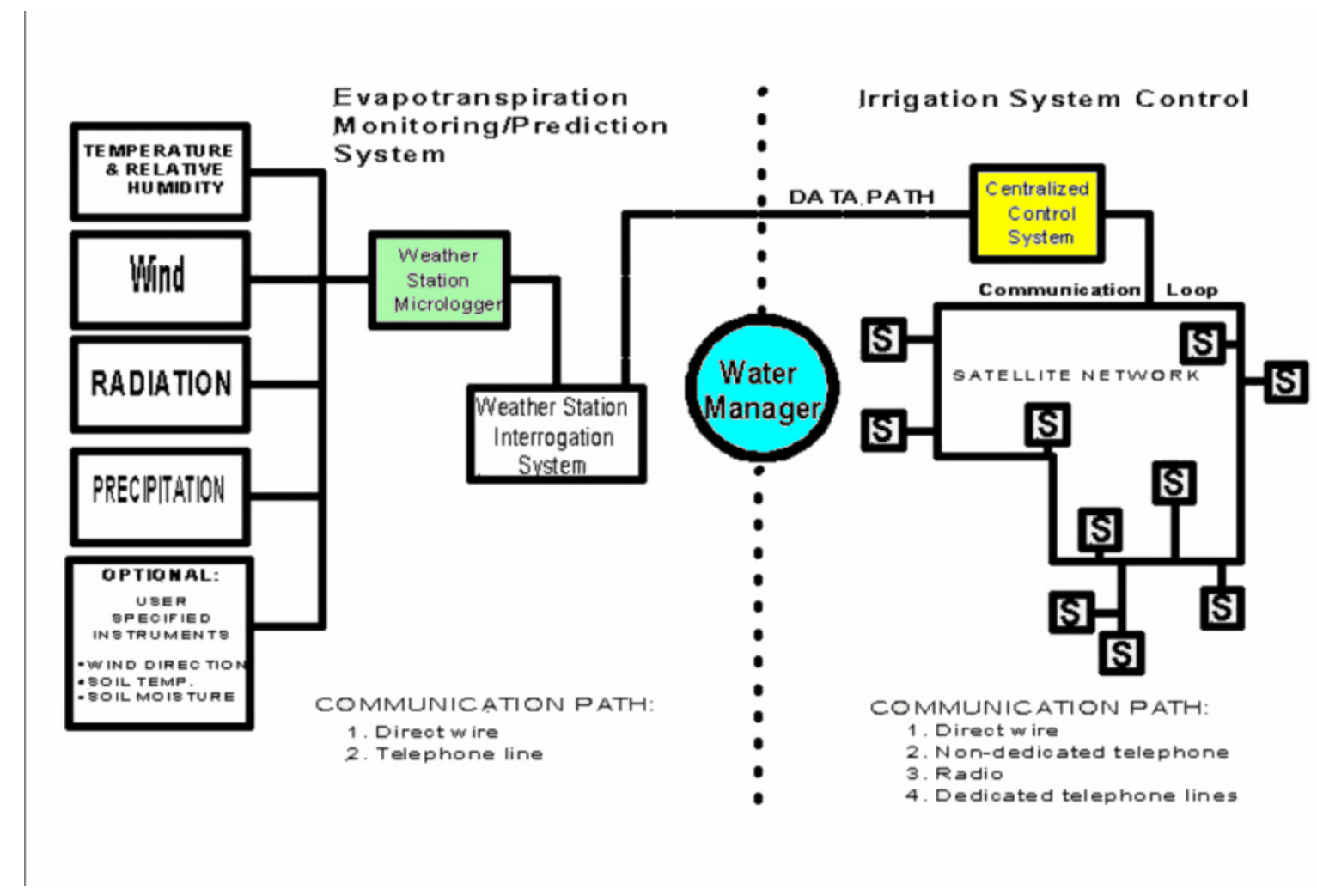

Figure 15. Schematic of central control system with weather station input to control irrigation events.

with regards to support and service once the equipment is installed.

\section{$\underline{\text { Differing Philosophies }}$}

A look at the overall philosophy of system operation can be enlightening and helpful in evaluating different systems. The control or management hierarchy built into the system and components is indicative of the system's basic philosophy. As a potential user, it is important to understand this philosophy to assure that it can be used and applied or adapted to current irrigation practices. A change in management style to match the imposed style of the system is probably not desirable.

The philosophy of some control systems includes a system with middle management. The central system communicates with a site having a cluster control unit (or CCU) at the site (Fig. 16). The CCU is in turn linked by hard wire or radio to a satellite controller. The satellite controller contains the terminal strip where the control and common wires are connected to valves. The CCU contains a computer (making it programmable and smart) and provides the middle management role in placement and hierarchy within the communication link. The CCU contains all the programs or schedules for a site. In addition, the CCU can perform actions such as closing valves in response to a high flow condition

In contrast, other systems are exemplary of a direct central to satellite management and communication philosophy. The central communicates by radio or telephone directly to satellite controllers. The satellite controller may see an alarm condition (say a high flow condition at a flow meter) and the satellite reacts, reporting actions taken when polled by the central. The central itself is programmed automatically to contact the site following each irrigation cycle. This communication process is full two-way communication between the central and the satellite controller.

\section{$\underline{\text { Distinguishing Capabilites }}$}


Exciting new features have become available including:

- A communication approach configured by site (telephone to farm, radio to a another farm, etc.).

- Alarms or alpha-numeric messages sent directly to pagers worn by maintenance personnel.

- Automated interrogation of weather stations and automatic ET data utilization.

- Prediction of soil moisture storage based on the checkbook or water balance method of irrigation scheduling.

- User-developed condition statements (if, then, else commands) used to create specific alarms.

- Multi-tasking environments which set the stage for dramatically expanded features in the future.

\section{Operation of Control Systems}

The information supplied from most irrigation systems is usually in the form of pressure and flow rate data. In some systems, additional parameters such as the level in a canal or pond, or an indication of a booster are used. The sensors supplying the information are mainly pressure gauges and flow meters with transducers adapted for telemetry and microswitches for level indication. Where transfer distances are short, the data can be supplied to the central computer as an analog output, by variation of the electric potential. Such data transfer requires an individual connection for every sensor or switch, making the installation rather expensive and complicated. Therefore, in control systems involving long transfer distances, the data are encoded near the transducer units for transfer by a single channel.

In direct transfer systems, the central unit collects the instantaneous data by scanning the sensors, one after another. Depending on the number of various sensors, the scan may last several seconds or more, so that the data received from a specific sensor reach the central computer intermittently, the interval between readouts depending on the scanning speed. The central unit receiving the data from a sensor averages four or five consecutive readings, in order to avoid recording accidental transient data peaks or dips which may occur throughout the scanning period and bias the output. The average is then processed by the computer and usually compared to the time parameter for calculation of flow rates or for totaling the flow volumes. The processed data can be displayed digitally or graphically, stored on magnetic media for further reference and printed as necessary.

Larger systems use intermediate field units (Fig. 14, No.1) which can collect data, each from a small number of sensors, reducing the scan period. The partially processed data are then transferred into the central unit by the same scanning method. Often the intermediate units can also act as self-contained computers, which can be specially programmed for either data display or for automatic control of the piping sector assigned to them. Such operation is independent of their main function of transferring data from sensors to the central computer or of conveying commands from the central computer to the various control devices.

T'he control systems are usually powered through the central unit, which is sometimes plugged directly into the main electric utility line, but more often connected through a rechargeable battery with a trickle charger. In order to ensure continuous operation of the control system and to avoid loss of data in case of power failure, an uninterrupted power supply unit and a lightening protector are included in the power units (Fig. 5, No.8).

Where utility supply power is not available, power for the control system can be provided by solar panels or from generators on diesel units.

Intermediate control units, which are typically located far from standard power lines, are frequently powered this way. Wiring of an irrigation control system should be done by a competent professional to insure that safety requirements are met and that the system meets the necessary codes. Most problems with irrigation controllers can be traced to poor electrical installation, particularly lack of adequate grounding. Wherever electronic components are used it is important that both signal and powerlines are protected from power surges. 
Communication between various units of the control system can be by wire or wireless. Data encoded by pulse requires two- or three-wire telephone cable in which one strand usually serves for energy supply from the source. For radio transmission the units are provided with radio transceivers, operating on the usual personal phone frequencies. One common practice is to connect the various sensors by wires to the intermediate unit, which then encode the data and forwards them to the central computer by radio or by wire. Where possible, the central computer and each field unit is provided with a modem and the data transmitted by ordinary telephone utility cables.

\section{Economics of Computer Control Systems}

Before any control system is chosen, an analysis of management and control alternatives should be performed. Project issues can typically be broken down into six categories:

- Control system factors.

- Communication factors.

- Existing Irrigation system factors.

- Management factors.

- Water factors.

- Economic or annual cost-of-money factors.

The primary control system factor, from the economic perspective, is cost. This includes the initial, installed cost of the control system and annual operating costs. The same is true of communication in that the initial cost and annual cost of communication must be determined to understand the respective cost implications. Telephone tends to have a lower initial cost than radio, but radio tends to have a lower annual cost. Only a thorough analysis indicates which is most cost effective. Further, if a particular control system is only suitable with radio, or conversely with telephone, then the system must be analyzed with this limitation in mind.

An inventory of the existing irrigation system is necessary. The number, location, and relative size of existing independent controllers must be known before a replacement concept can be developed. Historic applications and practices must be known in order to compare past practice with future practice. Water factors include the current availability and unit cost of pumping water in addition to the projected future availability and rate increases.

The historic ET rate for the area must be known to ascertain management alternatives and develop a water management strategy. The annual costs that may be effected by central control implementation must be determined and economic factors such as rate of inflation, cost of money, and economic life must be estimated.

All of these factors can best be analyzed with a spreadsheet. A sensitivity analysis on the data can often provide much insight into the decision process. Oftentimes, other factors such as reliability, ease of use, dealer support, and maintenance requirements are more important than overall cost.

\section{References}

Zazueta, F. S., A. G. Smajstrla, and G. A. Clark. 1993. Irrigation system controllers. Univ. of Florida., IFAS, Coop. Exten. Pub. AGE-32. 